\title{
Esophageal Cancer in North West India: A Tertiary Care Center Experience of 5 Years
}

\author{
Falak Khan', Rohitashwa Dana², Pawan Kumar ${ }^{3}$
}

${ }^{1}$ MD Radiation Oncology, Junior Resident Doctor, Department of Radiation Oncology SMS Hospital, Jaipur, India. ${ }^{2}$ MD Radiation Oncology, Senior Professor and Unit Head, Department of Radiation Oncology SMS Hospital, Jaipur, India. ${ }^{3}$ MD Radiation Oncology, Senior Resident Doctor, Department of Radiation Oncology SMS Hospital, Jaipur, India.

\begin{abstract}
Background: Incidence of Esophageal cancer (EC) is increasing now a days and it has became a sixth leading cause of cancer related death in world. EC is associated with multiple risk factors. Despite various advances in the treatment of EC, it remains one of the least responsive tumors to cancer therapy, thereby overall prognosis remains poor. The current status of EC in North West India in relation to the demographics, diagnosis, staging, multimodality treatment, and the future perspectives are discussed. Methods and Materials: This is a retrospective analysis of medical records of the EC patients registered in the Department of Radiation Oncology SMS Medical and Attached Hospitals Jaipur from January 2015 to December 2019. Results: Out of 10,464 patients with various malignancies registered in SMS hospital for radiotherapy via Co-60 technique in the previous 5 years from 2015-2019; 449 were having EC. $40.25 \%$ patients were in $6^{\text {th }}$ decade and male to female ratio was 1.49:1. EC was most common in farmers $(51.79 \%)$ and $76.16 \%$ patients were the resident of rural areas addicted with smoking $(41.4 \%)$ and tobacco chewing $(24.7 \%)$ habit. Dysphagia was the presenting feature in almost all the patients. Most common type and site of involvement were squamous type (75.72\%) and middle third $(45.43 \%)$ part of the esophagus respectively. $39.19 \%$ patients presented in stage III and $24.70 \%$ patients in stage IVA. The patients were planned with treatment according to their age, performance status, extent of disease and other co-morbidities. Conclusions: At our centre most of the patients landed up in advanced stage poverty, illiteracy, ignorance, late diagnosis. Majority of the EC patient were addicted with smoking and tobacco chewing habit, hence screening of high risk population and lifestyle modifications limiting the use of tobacco, may help in the early detection and can decrease the mortality related to EC. Careful selection of patients for radical treatment is very important for providing relatively longer disease free interval.
\end{abstract}

Keywords: Esophageal cancer- Northwest India- Demographics- Co-60- Multimodality treatment

\section{Introduction}

Esophageal Esophageal cancer (EC) is the eighth most common cancer worldwide, accounting for $3.2 \%$ of total new cases [1]. About $80 \%$ cases of EC worldwide occur in less developed regions [2]. According to GLOBOCAN 2018 estimates, in India, there were 52,396 new cases of EC, the incidence being $4.5 \%$ of all new cancer cases, and 46,504 (5.9\%) deaths were caused due to EC. Most common type is squamous type in developing countries like India while incidence of adenocarcinoma is more in developed countries [3, 4]. Risk factors associated with squamous cell carcinoma is smoking, alcohol abuse, tobacco addiction and poor nutrition [5]. Despite various advances in the treatment of EC, it is one of the least responsive tumors to cancer therapy, and the overall prognosis remains poor.

The treatment outcome varies across the regions and it reflects not only the incidence and expertise but also various patient and tumor related factors. Since beginning esophagectomy is the main treatment of EC but the results of the CROSS randomized clinical trial [6] can be considered an important landmark in the treatment of EC. This trial demonstrated the

Corresponding Author:

Dr. Falak Khan

Department of Radiation Oncology, SMS Hospital Jaipur, Rajasthan, India, 302004.

Email: falakk932@gmail.com 
superiority of neoadjuvant chemoradiotherapy (CRT) plus esophagectomy over surgery alone in the OS of esophageal and gastroesophageal junction cancers, which makes trimodal therapy the current standard of treatment of locally advanced EC. Despite these results, 2 European trials showed the possibility of upfront concurrent definitive CRT (dCRT) as a possible treatment of locally advanced ESCC [7, 8]. Currently, this modality has been advocated for patients who decline or who are unsuitable for esophagectomy [9].

A better understanding of the etiology/risk factors, pattern of presentation of disease may suggest opportunity for its primary prevention. In view of this we have done retrospective study of biopsy proven esophageal cancer patients visiting Department of Radiation Oncology SMS Medical College and Hospitals Jaipur during a period of January 2015 to December 2019 in relation to the demographics, diagnosis, staging, treatment and the future perspectives for the better outcome of the disease.

\section{Materials and Methods}

This was a retrospective hospital record based study carried out in Department of Radiation Oncology SMS Medical College and Attached Hospitals Jaipur Rajasthan, India. For extracting data the radiotherapy files of the cancer patients registered in the hospital were collected from January 2015 to December 2019. A total of 10,464 patients with a variety of malignancies were registered in the last 5-year duration for RT with Cobalt-60 technique. Out of this, 449 were diagnosed to have EC. The parameters including age, gender, locality, occupation, addiction, staging and treatment patterns of the patients were studied. The site of the disease and the histology were also recorded.

\section{Results}

-A total of 449 patients were retrospectively analyzed with sociodemographic and clinical parameters at presentation to the hospital are summarized in Table 1 and Table 2 below.

- $40.25 \%$ patients presented in the $6^{\text {th }}$ decade of life with male preponderance and male to female ratio of 1.49:1 was there.

- $76.16 \%$ were the resident of rural area and $51.79 \%$ study population was farmer by occupation.

- Smoking $(41.4 \%)$ being the most common risk factor for EC.

\section{Clinical Characteristics of the patients}

- All the patients presented at our center with the chief complaints of dysphagia for solids $(100 \%)$ or for solids and liquid both (67\%).

- Squamous cell carcinoma (75.72\%) was the most common histology with middle third esophagus (45.43\%) being the most common site of disease.

- Majority of the patients presented in stage III and IVA, $39.19 \%$ and $24.70 \%$ respectively and $14.47 \%$ of the patients were with metastasis at different site with liver
Table 1. Patients Characteristics

\begin{tabular}{|c|c|c|}
\hline $\begin{array}{l}\text { Various } \\
\text { Parameters }\end{array}$ & Observation & $\begin{array}{c}\text { Total number of } \\
\text { Patients } N=449(\%)\end{array}$ \\
\hline Age & $<40$ & $48(10.76)$ \\
\hline \multirow[t]{3}{*}{ (years) } & $41-50$ & $87(19.74)$ \\
\hline & $51-60$ & $131(29.23)$ \\
\hline & $>60$ & $183(40.25)$ \\
\hline \multirow[t]{2}{*}{ Gender } & Male & $269(59.9)$ \\
\hline & Female & $180(40.25)$ \\
\hline \multirow[t]{2}{*}{ Residential Area } & Rural & $342(76.16)$ \\
\hline & Urban & $107(23.83)$ \\
\hline \multirow[t]{2}{*}{ Education } & Illiterate & $276(61.46)$ \\
\hline & Literate & $173(38.5)$ \\
\hline \multirow[t]{5}{*}{ Occupation } & Farmer & $233(51.79)$ \\
\hline & Housework & $102(22.82)$ \\
\hline & Self employed & $21(4.8)$ \\
\hline & Labourer & $62(13.84)$ \\
\hline & Service & $31(6.66)$ \\
\hline \multirow{5}{*}{$\begin{array}{l}\text { Socioeconomic } \\
\text { status }\end{array}$} & Upper & $26(5.79)$ \\
\hline & Upper middle & $39(8.68)$ \\
\hline & Lower middle & $63(14.03)$ \\
\hline & Upper lower & $144(32.07)$ \\
\hline & Lower & $177(39.42)$ \\
\hline \multirow[t]{4}{*}{ Personal habits } & Smoking & $186(41.4)$ \\
\hline & Tobacco chewing & $111(24.7)$ \\
\hline & Alcohol + smoking & $84(18.7)$ \\
\hline & No addiction history & $68(15.2)$ \\
\hline
\end{tabular}

metastasis being the most common at presentation.

- $45.21 \%$ patients received definitive chemoradiotherapy (CRT) as 50-50.4Gy + concurrent chemotherapy and $40.50 \%$ planned with trimodality therapy (RT 41.4-50.4Gy + concurrent chemotherapy) followed by surgery.

- Patients with metastasis at presentation were planned with palliative radiotherapy (RT) for symptomatic relief for dysphagia, pain and bleeding.

\section{Discussion}

Esophageal cancer is an upper digestive tract cancer, mainly prevalent in developing and underdeveloped countries. In our study, $10.76 \%$ patients were of $\leq 40$ years and majority of patients were in elderly age group with $40.25 \%$ presenting in age more than 60 years. It has been found that $\mathrm{EC}$ is rare in individuals younger than age 30 in both low and high incidence areas; EC cases in those $\leq 30$ years of age in northern China, northeastern Iran, and the Surveillance, Epidemiology, and End Results (SEER) registries in the US account for $0.7,1$, and $0.5 \%$ of cases, respectively $[10,11,12]$. Another Indian study by Chitra et al., also reported similar age patterns with $5 \%$ cases below the age of 40 years with majority $62 \%$ cases of age group 41-60 year [13]. These studies were corroborating with the findings of this study. Though it is more common in males, the rate is increasing in females also. In the 
Table 2. Clinical Characteristics of Patients

\begin{tabular}{|c|c|c|}
\hline Clinical Characteristics & Observation & Total Number of Patients $\mathrm{N}=449(\%)$ \\
\hline \multirow[t]{5}{*}{ Presenting symptoms } & Dysphagia & $449(100)$ \\
\hline & Odynophagia & $267(59.40)$ \\
\hline & Regurgitation & $257(57.23)$ \\
\hline & Chest pain & $182(40.53)$ \\
\hline & Weight loss $(>5 \%$ of TBW $)$ & $265(59.02)$ \\
\hline \multirow[t]{3}{*}{ Duration of symptoms (months) } & 1-3 months & $266(59.25)$ \\
\hline & 3-6 months & $100(22.27)$ \\
\hline & $>6$ months & $83(18.51)$ \\
\hline \multirow[t]{3}{*}{ Histology } & Squamous cell carcinoma & $340(75.72)$ \\
\hline & Adenocarcinoma & $83(18.48)$ \\
\hline & Undifferentiated & $26(5.79)$ \\
\hline \multirow[t]{4}{*}{ Site of disease } & Upper esophagus & $101(22.4)$ \\
\hline & Middle esophagus & $204(45.43)$ \\
\hline & Lower esophagus & $139(30.95)$ \\
\hline & Insufficient data & $5(1.11)$ \\
\hline \multirow[t]{5}{*}{ Stage at Presentation } & I & 0 \\
\hline & II & $97(21.6)$ \\
\hline & III & $176(39.19)$ \\
\hline & IVA & $111(24.7)$ \\
\hline & IVB & $65(14.47)$ \\
\hline \multirow[t]{4}{*}{ Metastasis at presentation } & Liver & $22(4.89)$ \\
\hline & Cervical lymph nodes & $17(3.78)$ \\
\hline & Lung & $14(3.11)$ \\
\hline & Bone & $12(2.67)$ \\
\hline \multirow[t]{3}{*}{ Treatment taken } & Neoadjuvant CRT f/b surgery & $181(40.5)$ \\
\hline & Definitive CTRT & $203(45.21)$ \\
\hline & Palliative RT (as indicated) & $65(14.47)$ \\
\hline
\end{tabular}

present study, we observed a male preponderance with a male to female ratio of $1.49: 1$. Similarly, a study done by Sankaranarayanan $\mathrm{R}$ et al.[14] found that the proportions of males was higher than females with ratio of $2: 1$. Another study done by Sehgal $\mathrm{S}$ et al.[15] also showed higher proportions of males than females with ratio of 2.1:1. Almost all of the patients in this study were presented with dysphagia as a chief presenting complaint and dysphagia was also the most common indication for upper GI endoscopy. Vishal Gupta et al find same type of presentation in his study [16].

In our study, about two-third of the EC patients were illiterate and half belonged to low socioeconomic status as per the modified BG Prasad scale. Sehgal et al.[15], also reported that the majority (63\%) cases were illiterate and $59.5 \%$ from lower socioeconomic status. Thus, our data are in agreement with already published literature. The occupation that had highest relation with EC was found to be farming as farm based earning of livelihood is more prevalent in north-west India.

In our study, $22.4 \%$ patients had the malignancy of upper third of the esophagus; $45.43 \%$ patients had middle and $30.95 \%$ had carcinoma of the lower esophagus. In $1.11 \%$ of the patients, insufficient data were available to locate the exact site of the lesion. In another study by Giri et al., the percentage of patients with upper, middle, and lower third cancer was $9.66,40.57$, and $49.76 \%$, respectively [17]. In our study, $18.48 \%$ patients had adenocarcinoma, while $75.72 \%$ had SCC and in $5.79 \%$ cases, the histology revealed undifferentiated carcinoma. Western literature has reported alcohol and tobacco use to the major risk factor for SCC, accounting for $80-90 \%$ of the cases [18]. In the present study also, the addiction of smoking was present in the majority (41.4\%) of the patients. Alcohol and smoking abuse together was reported by $18.7 \%$ of the patients. Esophageal SCC risk is 4.2 times higher in current smokers in Europe compared with never-smokers, a meta-analysis showed [19].

\section{The SMS Hospital Jaipur Experience}

The 5 year experience (2015-2019) of the patients with respect to the sociodemographic and clinical parameters at presentation, to our institute are summarized in (Table 1) and (Table 2) respectively. All the patients were inoperable at presentation and majorities (39.19\%) of them were in stage III. Of total 449 patients 181 were planned with NACRT (41.4-50.4Gy, with paclitaxel and carbobplatin) followed by surgery. Majority (45.21\%) of patients were 
treated with definitive CTRT (50-50.4Gy). 65 patients presented with metastatic disease with liver metastasis $(n=22,4.89 \%)$ being the most common and were treated symptomatically with palliative radiotherapy for the symptoms of pain, dysphagia, bleeding and others as indicated. Adequate caloric intake oral and/or enteral and IV hydration was maintained throughout chemoradiation and recovery.

\section{Limitations}

Lack of availability of the dietary habits of the patients.

In conclusion, the incidence of esophageal cancer in India is rising, but very limited data is available. Older age, male gender, lower socio economic status, smoking habit mostly contributes to development of EC. Cancer preventive measures and screening programs should be employed for the early detection of cancer. The most feasible method to reduce esophageal cancer burden is to identify and target etiological factors, improve socio-economic status, and screen the high-risk group of people as well as generating awareness regarding modification of lifestyle.

\section{References}

1. gco.iarc.fr/data/fact-sheets/population/900-world-factsheets (GLOBACON 2018). gco.iarc.fr/data/factsheets/ population/356-india-fact-sheets (GLOBACON 2018).

2. Parkin DM, Bray F, Ferlay J, Pisani P. Global Cancer Statistics, 2002. CA: A Cancer Journal for Clinicians. 2005 03 01;55(2):74-108. https://doi.org/10.3322/canjclin.55.2.74

3. Malkan G, Mohandas K. Epidemiology of digestive cancers in India. I. General principles and esophageal cancer. Indian J Gastroenterol. 1997;16:98-102.

4. Chen J, Zhang N, Ling Y, Wakai T, He Y, Wei L, Wang S, Akazawa K. Alcohol Consumption as a Risk Factor for Esophageal Adenocarcinoma in North China. The Tohoku Journal of Experimental Medicine. 2011;224(1):21-27. https://doi.org/10.1620/tjem.224.21

5. Das K, Singh S, Pawar G, Masih R, Raju N. Risk factors analysis of squamous cell carcinoma (SCC) esophagus in North Indian females in tertiary care hospital: A case-control study. Int J Recent Sci Res. 2015;6:4661-4.

6. Shapiro J, van Lanschot JJB, Hulshof MCCM, van Hagen P, van Berge Henegouwen MI, Wijnhoven BPL, van Laarhoven HWM, Nieuwenhuijzen GAP, Hospers GAP, Bonenkamp JJ, Cuesta MA, Blaisse RJB, Busch ORC, ten Kate FJW, Creemers GM, Punt CJA, Plukker JTM, Verheul HMW, Bilgen EJS, van Dekken H, van der Sangen MJC, Rozema T, Biermann K, Beukema JC, Piet AHM, van Rij CM, Reinders JG, Tilanus HW, Steyerberg EW, van der Gaast A. Neoadjuvant chemoradiotherapy plus surgery versus surgery alone for oesophageal or junctional cancer (CROSS): long-term results of a randomised controlled trial. The Lancet Oncology. 2015 09;16(9):1090-1098. https://doi. org/10.1016/s1470-2045(15)00040-6

7. Bedenne L, Michel P, Bouché O, Milan C, Mariette C, Conroy T, Pezet D, Roullet B, Seitz J, Herr J, Paillot B, Arveux $\mathrm{P}$, Bonnetain F, Binquet C. Chemoradiation Followed by Surgery Compared With Chemoradiation Alone in Squamous Cancer of the Esophagus: FFCD 9102. Journal of Clinical Oncology. 200704 01;25(10):1160-1168. https:// doi.org/10.1200/jco.2005.04.7118

8. Stahl M, Stuschke M, Lehmann N, Meyer H, Walz MK, Seeber S, Klump B, Budach W, Teichmann R, Schmitt M, Schmitt G, Franke C, Wilke H. Chemoradiation With and Without Surgery in Patients With Locally Advanced Squamous Cell Carcinoma of the Esophagus. Journal of Clinical Oncology. 200504 01;23(10):2310-2317. https://doi.org/10.1200/ jco.2005.00.034

9. National Comprehensive Cancer Network: NCCN Guidelines Version 2.2019 Esophageal and Esophagogastric Junction Cancers. https://www.nccn.org/professionals/physician_gls/ pdf/esophageal.pdf Google Scholar.

10. Zhang H. Epidemiological investigation of esophageal carcinoma. World Journal of Gastroenterology. 2004;10(12):1834. https://doi.org/10.3748/wjg.v10. i12.1834

11. Semnani S, Besharat S, Abdolahi N, Kalavi K, Fazeli S, Davarian A, et al. Esophageal cancer in northeastern Iran. Indian J Gastroenterol. 2005;24:224.

12. Surveillance, Epidemiology, and End Results (SEER) Program Populations (1969-2012), National Cancer Institute, DCCPS, Surveillance Research Program, Cancer Statistics Branch. Available from: http://www.seer.cancer. gov/popdata [Last accessed on Dec 2014].

13. Chitra S, Ashok L, Anand L, Srinivasan V, Jaynath V. Risk factors for oesophageal cancer in Coimbatore; Southern India: A hospital based case control study . Indian J Gastroenterol. 2004;23:19-21.

14. Sankaranarayanan R, Duffy SW, Padmakumary G, Nair SM, Day NE, Padmanabhan TK. Risk factors for cancer of the oesophagus in Kerala, India. International Journal of Cancer. 1991 Oct 21;49(4):485-489. https://doi.org/10.1002/ ijc.2910490402

15. Dhar M, Sehgal S, Kaul S, Gupta B. Risk factors and survival analysis of the esophageal cancer in the population of Jammu, India. Indian Journal of Cancer. 2012;49(2):245. https://doi.org/10.4103/0019-509x.102921

16. Gupta V, Bhardwaj S, Bhagat OK. Pattern of esophageal cancer in tertiary care hospital in North India: a clinicopathological study. International Journal of Research in Medical Sciences. 201703 28;5(4):1405. https://doi.org/10.18203/2320-6012. ijrms20171235

17. Giri PA, Singh KK, Phalke DB. Study of socio demographic determinants of esophageal cancer at a tertiary care teaching hospital of Western Maharashtra, India. South Asian Journal of Cancer. 2014 01;03(01):054-056. https://doi. org/10.4103/2278-330x.126526

18. Schottenfeld D. Epidemiology of cancer of the esophagus . Semin Oncol. 1984;11:92-100.

19. Prabhu A, Obi KO, Rubenstein JH. Systematic review with meta-analysis: race-specific effects of alcohol and tobacco on the risk of oesophageal squamous cell carcinoma. Alimentary Pharmacology \& Therapeutics. 201309 30;38(10):1145-1155. https://doi.org/10.1111/apt.12514

This work is licensed under a Creative Commons AttributionNon Commercial 4.0 International License. 